\title{
Simulation Analysis and Experiment of Instantaneous Temperature Field for Grinding Face Gear with A Grinding Worm
}

Hui Guo ( $\sim$ guohui502@nwpu.edu.cn )

Northwestern Polytechnical University

Xuyang Wang

Ning Zhao

Bibo Fu

Li Liu

\section{Research Article}

Keywords: Face gear, Worm wheel, Temperature field, Finite element analysis, Gear grinding

Posted Date: February 9th, 2022

DOI: https://doi.org/10.21203/rs.3.rs-1313578/v1

License: (c) (1) This work is licensed under a Creative Commons Attribution 4.0 International License.

Read Full License 


\title{
Simulation analysis and experiment of instantaneous temperature field for grinding face gear with a grinding worm
}

\author{
Hui Guo ${ }^{\mathrm{a}, *}$, Xuyang Wang ${ }^{\mathrm{a}}$, Ning Zhao ${ }^{\mathrm{a}}$, Bibo Fu ${ }^{\mathrm{b}}$, Li Liu ${ }^{\mathrm{b}}$ \\ ${ }^{a}$ School of Mechanical Engineering, Northwestern Polytechnical University, Xi'an 710072, CHINA \\ ${ }^{b}$ Transmission System Center, AECC Hunan Aviation Powerplant Research Institute, Zhuzhou 412002, CHINA
}

\begin{abstract}
In this paper, a transient temperature calculation model for simulating grinding face gear with a grinding worm is proposed. Firstly, according to the principle of differential geometry, the equations for determining contact arc length and contact width of the instantaneous grinding area between the worm grinding wheel and the face gear are deduced. Based on the method for the single abrasive particle cutting force and grinding heat, a mathematical model for the grinding force and grinding heat of the face gear is established, and the theoretical calculation formula of the instantaneous maximum temperature for grinding teeth of the face gear is obtained. Secondly, a finite element model of temperature field for face gear grinding with moving heat load of grinding worm wheel is established, and the influence law of grinding process parameters on tooth surface temperature is studied. Finally, the validity of the temperature field simulation model is verified by multi-group temperature testing experiments for face gear grinding.
\end{abstract}

Key words: Face gear, Worm wheel, Temperature field, Finite element analysis, Gear grinding

\section{Introduction}

Face gear transmission has the advantages of high contact ratio, convenient installation and wide range of transmission ratio[1]. It has been successfully applied in helicopter split-torque transmissions and automotive differential mechanisms. Face gears after carburizing and quenching can be continuously generated and ground by a worm wheel to improve its tooth profile precision and tooth pitch accuracy. However, improper grinding process parameters will make excessive thermal energy concentrated in the grinding zone [2], which will cause very high surface temperature on the gear teeth, and then result in burn and even surface cracks. Therefore, finding appropriate grinding process parameters is important for improving the machining efficiency and tooth surface quality of the face gear.

In terms of grinding thermal analysis theory, many researchers studied machining thermal generation for plane and common gears. Outwater[3] assumed that most of the grinding heat is generated around the shear surface of the workpiece, and proposed the heat source theory of the shear

\footnotetext{
*Corresponding author

Email address: guohui 502@nwpu. edu.cn (Hui Guo )
} 
surface, and obtained the heat source model of the heat diffusion to the workpiece. From the perspective of grinding energy, Hahn[4] realized that most of the heat was generated on the abrasive wear plane, and proposed a sliding assumption model of abrasive particles. Bei[5] established a theoretical model of the triangular heat source, derived the calculation formula for the temperature of the grinding zone, and carried out measurement experiments on the grinding temperature, which enriched the types of research models. Rowe[6] established a heat transfer process model considering the grinding wheel speed, cutting depth and grinding contact arc length in grinding. Based on Rowe's theoretical model, Guo[7] improved the grinding heat distribution ratio model by taking into account the interaction between abrasive particles, workpieces and coolant. Jing $\mathrm{Li}[8]$ et al. used ABAQUS software to conduct a finite element simulation of three-dimensional heat transfer in grinding quartz material, and focused on the distribution of the temperature field of the workpiece under dry and wet grinding conditions, and found that for the same heat source, the convective heat transfer coefficient has little effect on the temperature contour shape of the contact surface. Yan [9] established a 3D finite element model of the transient temperature field of the spiral bevel gear grinding. The simulation result shows that the maximum transient temperature of the grinding gear is much greater than the steady-state temperature, and the position of the transient maximum temperature is in the center of the grinding area. Zhao[10] et al. analyzed the temperature distribution on surface and in the direction of cutting depth, and studied the influence of heat source shape and contact length on the grinding temperature distribution. Appropriate material removal rate is beneficial to improve the surface quality. Based on the transient moving heat source temperature field theory, Jya[11] established a temperature calculation model for grinding gear teeth by forming wheel, and studied the coupling effect of the temperature of adjacent grinding points on the surface of cylindrical spur gears. Due to the coupling effect of adjacent heat sources, the temperature distribution on the surface of the gullet during the tooth processing is not uniform in forming grinding .

Some work about the tooth grinding method and grinding temperature field of face gears has been carried out. Litvin et al.[12,13] proposed a theory based on the grinding worm wheel generation face gear, gave the equation of the worm wheel, and studied the singularity characteristics of the grinding worm wheel. $\mathrm{Li}[14]$ et al. studied the base worm surface equation of the face gear hobbing tool, and found that the tool base worm and the orthogonal face gear are in form of point contact, and the equation of the instantaneous contact point in machining was deduced. Guo et al.[15] established a theoretical model of the six-axis CNC worm grinding machine for grinding face gears, and present a method of dressing ellipsoidal grinding worm wheel with diamond dressing tool, which takes the initially designed tooth profile of grinding worm wheel shaft section as the basic parameter and considers the parabola modification of tooth profile. Experiments have verified that the face gears ground by this method can obtain higher precision. Chu[16] et al. proposed a method of grinding face gears along the contact trajectory using a disk-shaped CBN grinding wheel, and carried out the grinding experiment of the face gears on a five-axis grinding machine. Ming et al.[2] established a finite element model grinding face gear for the temperature field with the disc grinding wheel. The simulation results show that the temperature gradient is large in the first period of the grinding time, while gentle in the second period.

The grinding worm wheel has a high rotational speed, and its grinding process is different from that of the disc wheel. In current research literatures, there is no research report on the temperature 
field about grinding face gear with a worm wheel. In order to obtain the grinding temperature of face gears under different process parameters, this paper focuses on the following issues:

(1) The calculation model of grinding force and heat of grinding face gear with a grinding worm wheel is established, and then the theoretical calculation value of the maximum steady-state temperature at the grinding point of the face gear tooth surface is obtained.

(2) The finite element calculation model for the temperature field of grinding face gear under the condition of moving thermal load is established, and the simulation results of the maximum transient temperature at the grinding point are compared with the theoretical calculation value of the steady-state maximum temperature. The temperature variation of face gears under different grinding process parameters is studied.

(3) The grinding temperature of the center point on the tooth surface is measured by the infrared temperature measurement method for different processing parameters.

\section{Grinding principle of face gear with a worm wheel}

\subsection{Grinding process of face gear with a worm wheel}

Grinding face gear with a worm wheel is a machining process based on the principle of doubleparameter generation[1]. The grinding worm wheel simulates the shaper gear that meshes with the face gear. The tooth profile of the grinding wheel in the normal section is an approximate involute profile, and the grinding worm wheel is in instantaneous point contact with the face gear. When they mesh with each other according to a given transmission ratio $i=\omega_{w} / \omega_{2}$, it will generate a strip of tooth profile at a certain position on the tooth width of the face gear. The grinding worm wheel feeds along the longitudinal direction of the tooth to complete the machining of the entire tooth surface. In order to avoid over large grinding force and excessive grinding heat, it is necessary to make the grinding wheel feed along the tooth depth direction of the face gear with a small amount every time. In addition, the rotating speed of the grinding worm and longitudinal feed speed will also affect the maximum grinding temperature of the tooth surface.

\subsection{Instantaneous contact ellipse during grinding}

\subsubsection{Principal curvature and principal orientation of the tooth surfaces}

The tooth surface equation of the face gear and the grinding worm wheel can be expressed as:

$$
\mathbf{r}_{i}=\mathbf{r}_{i}(u, v) \quad(i=1,2)
$$

here, $u$ and $v$ are two surface parameters; $i=1$ represents the face gear; $i=2$ represents the grinding worm wheel; the detailed expressions for Eq.(1) can be found in reference [17].

The principal curvature equation of a smooth surface can be expressed as:

$$
\left|\begin{array}{cc}
k_{n}^{(i)} E-L & k_{n}^{(i)} F-M \\
k_{n}^{(i)} F-M & k_{n}^{(i)} G-N
\end{array}\right|=0 \quad(i=1,2 ; n=I, I I)
$$

where, $k_{I}^{(i)}$ and $k_{I I}^{(i)}$ are the first principal curvature and the second principal curvature at any point on the tooth surface of the grinding wheel or the face gear. The first principal curvature 


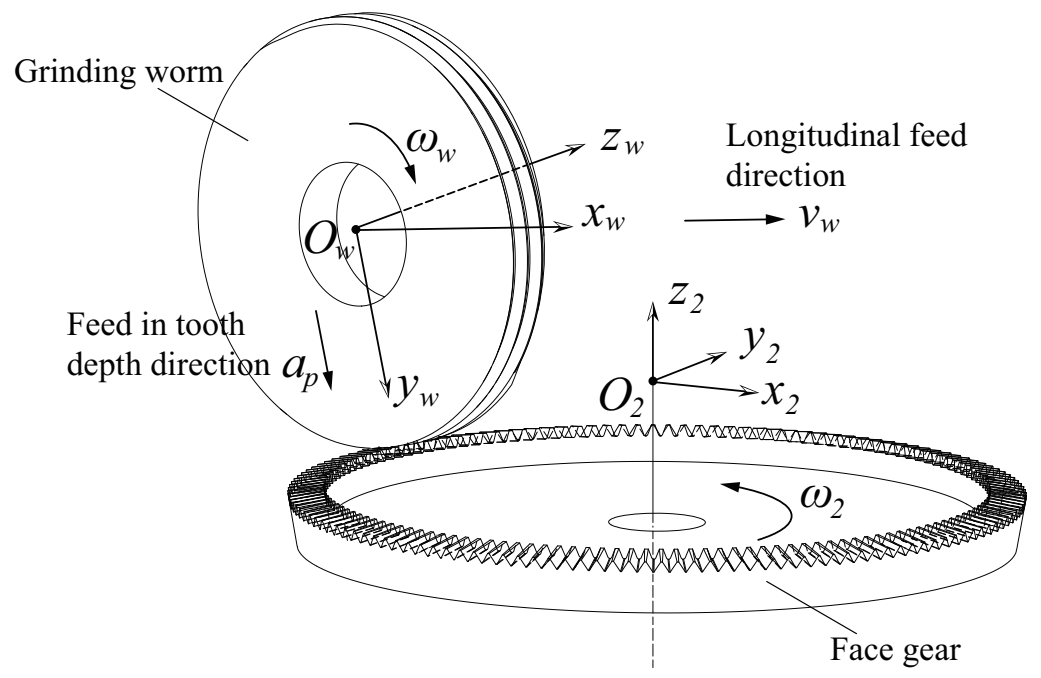

Figure 1: Schematic diagram of face gear with a grinding worm wheel.

is equal to the maximum normal curvature, and the second principal curvature is equal to the minimum normal curvature.

The principal direction equation of a surface can be expressed as the following determinant:

$$
\left|\begin{array}{cc}
E d u+F d v & F d u+G d v \\
L d u+M d v & M d u+N d v
\end{array}\right|=0
$$

By Eq.( 3), two different real solutions $\left[\frac{d u}{d v}\right]_{I}^{(i)}$ and $\left[\frac{d u}{d v}\right]_{I I}^{(i)}$ can be obtained, then the principle direction vector of the surface can be expressed as:

$$
\mathbf{e}_{n}^{(i)}=\mathbf{r}_{v}\left[\frac{d u}{d v}\right]_{n}^{(i)}+\mathbf{r}_{u} \quad(i=1,2 ; n=I, I I)
$$

Where, $n=I$, for the first principal direction vector, and $\mathbf{e}_{I}^{(i)}$ is the tooth surface tangent vector corresponding to the first principal curvature; $n=I I$ represents the second principal direction vector, and $\mathbf{e}_{I I}^{(i)}$ is the tooth surface tangent vector corresponding to the second principal curvature. $\mathbf{r}_{u}$ and $\mathbf{r}_{v}$ are two surface tangent vectors of the worm or the face gear.

In Eq.(2) and Eq.(3), $E, F$ and $G$ are the first basic quantities of the surface; $L, M$ and $N$ are the second basic quantities of the surface; they can be expressed as:

$$
\left\{\begin{array} { l } 
{ E = \mathbf { r } _ { u } \cdot \mathbf { r } _ { u } } \\
{ F = \mathbf { r } _ { u } \cdot \mathbf { r } _ { v } } \\
{ G = \mathbf { r } _ { v } \cdot \mathbf { r } _ { v } }
\end{array} \left\{\begin{array}{l}
L=-\mathbf{n}_{u} \cdot \mathbf{r}_{u} \\
M=-\mathbf{n}_{u} \cdot \mathbf{r}_{v} \\
N=-\mathbf{n}_{v} \cdot \mathbf{r}_{v}
\end{array}\right.\right.
$$

where, $\mathbf{n}_{u}$ and $\mathbf{n}_{v}$ is the partial derivative vector of $\mathbf{n}$ with respect to $u$ and $v$ respectively. $\mathbf{n}$ is the unit normal vector of the tooth surface. 


\subsubsection{Instantaneous contact ellipse}

During the grinding process, the worm wheel and the face gear are in point contact instantaneously. As shown in Figure 2, the instantaneous contact area can be considered as an ellipse. The short axis length $b$ of the ellipse is the contact width, and the long axis length $a$ is the contact length, i.e. the instantaneous contact arc length. $\mathbf{e}_{I}^{(1)}$ and $\mathbf{e}_{I}^{(2)}$ are the first principal direction vectors of the face gear and the grinding worm wheel at the grinding point respectively. $\alpha_{s}$ is the included angle of $\mathbf{e}_{I}^{(1)}$ and $\mathbf{e}_{I}^{(2)}$, and $\mathbf{n}$ is the external normal vector of the face gear unit. The vectors $\zeta, \eta$ and the unit normal vector $\mathbf{n}$ of the contact point form a right-handed coordinate system.

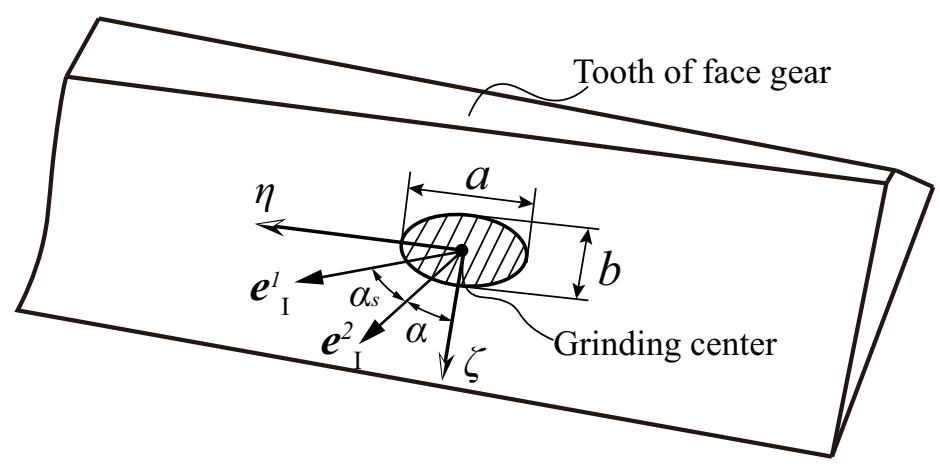

Figure 2: Instantaneous contact ellipse between the worm wheel and the face gear.

During grinding, the major and minor axes of the instantaneous contact ellipse between the grinding wheel and the face gear can be determined by:

$$
\left\{\begin{array}{l}
a=\sqrt{\left(\delta+a_{e}\right) / A} \\
b=\sqrt{\left(\delta+a_{e}\right) / B}
\end{array}\right.
$$

where, $A$ and $B$ are the geometric parameters related to the curvature and the contact direction between the two surfaces:

$$
\left\{\begin{array}{l}
A=\left[\Sigma^{(1)}-\Sigma^{(2)}-\left(\sqrt{g_{1}^{2}-2 g_{1} g_{2} \cos 2 \alpha_{s}+g_{2}^{2}}\right)\right] / 4 \\
B=\left[\Sigma^{(1)}-\Sigma^{(2)}+\left(\sqrt{g_{1}^{2}-2 g_{1} g_{2} \cos 2 \alpha_{s}+g_{2}^{2}}\right)\right] / 4
\end{array}\right.
$$

here, $\Sigma^{(i)}=k_{I}^{(i)}+k_{I I}^{(i)} ; g_{i}=k_{I}^{(i)}-k_{I I}^{(i)},(i=1,2) ; k_{I}^{(i)}$ and $k_{I I}^{(i)}$ represent the principal curvature of the contact point between the face gear and the grinding worm wheel respectively.

In Eq.(6), $a_{e}$ is the grinding depth along the normal vector of the tooth surface; $\delta$ is the elastic deformation of the tooth at the contact point of the face gear,

$$
\delta=\chi \sqrt[3]{\frac{9(A+B) F_{n}^{2}}{128} \cdot \frac{1-\mu_{1}^{2}}{E_{1}}}
$$

Where, $F_{n}$ represents the normal grinding force between the worm and the face gear; $E_{1}$ and $\mu_{1}$ are the material elastic modulus and the material Poisson's ratio of the face gear; coefficient $\chi$ is deformation coefficient with regard to the curvatures of two surfaces, and it can be obtained 
by interpolation with the relevant table according to parameters $A$ and $B$ [18]. Here, the grinding wheel is considered as a rigid body without deformation due to it's stiffness.

In Figure 2, the angle between the long axis of the contact ellipse $\eta$ and $\mathbf{e}_{I}^{(2)}$ is determined by:

$$
\alpha_{1}=0.5 \times \arctan \left[\frac{g_{2} \sin \alpha_{s}}{g_{1}-g_{2} \cos \alpha_{s}}\right]
$$

Without the normal grinding force $F_{n}$, the size of contact ellipse is unknown for now. Grinding force will be discussed in Section 3.

\subsection{Effective number of abrasive particles per unit area}

According to the model of Kalpakian[19], the actual number of abrasive particles involved in grinding per unit area on the grinding worm wheel can be expressed as:

$$
N_{d}=\frac{4 f}{d_{g}^{2} \cdot(4 \pi / 3 v)^{2 / 3}}
$$

here, $f$ is the percentage of effective abrasive particles, usually taken as 0.5 for general grinding material; $v$ is abrasive particle volume fraction, usually taken as $0.25 ; d_{g}$ is equivalent ball diameter of abrasive particles, $d_{g}=15.2 / M$, and $M$ is abrasive particle size.

\subsection{Average depth of cut for abrasive particles}

After the tooth surface is ground by abrasive particles, tiny nicks of different depths are produced. Since the abrasive particles are randomly distributed on the surface of the grinding wheel, the average grinding depth of the abrasive particles can be expressed as the following equation in combination with the Rayleigh probability density function[20]:

$$
\bar{a}_{g}=\sqrt{\frac{a_{e} v_{w}}{2 N_{d} v_{s}} \cdot \frac{1}{a}}
$$

where, $v_{w}$ is feed rate of grinding wheel along the tooth width; $v_{s}$ is the linear speed of the grinding worm wheel, which can be determined by the rotating speed $v_{r}$ and diameter $D_{w}$ of the worm, $v_{s}=\pi v_{r} D_{w} / 60 ; N_{d}$ is the number of effective abrasive particles per unit area of grinding wheel surface.

Figure 3 shows the relationship between the grinding amounts in tooth depth direction and in normal direction when the face gear is being ground. We use $a_{p}$ to represent the single-step feed amount along tooth depth of the face gear. Because of the pressure angle of the tooth profile, the single-step grinding depth $a_{e}$ along surface normal can be expressed as:

$$
a_{e}=a_{p} \sin \alpha
$$

here, $\alpha$ is the pressure angle of the face gear at the current grinding point. 


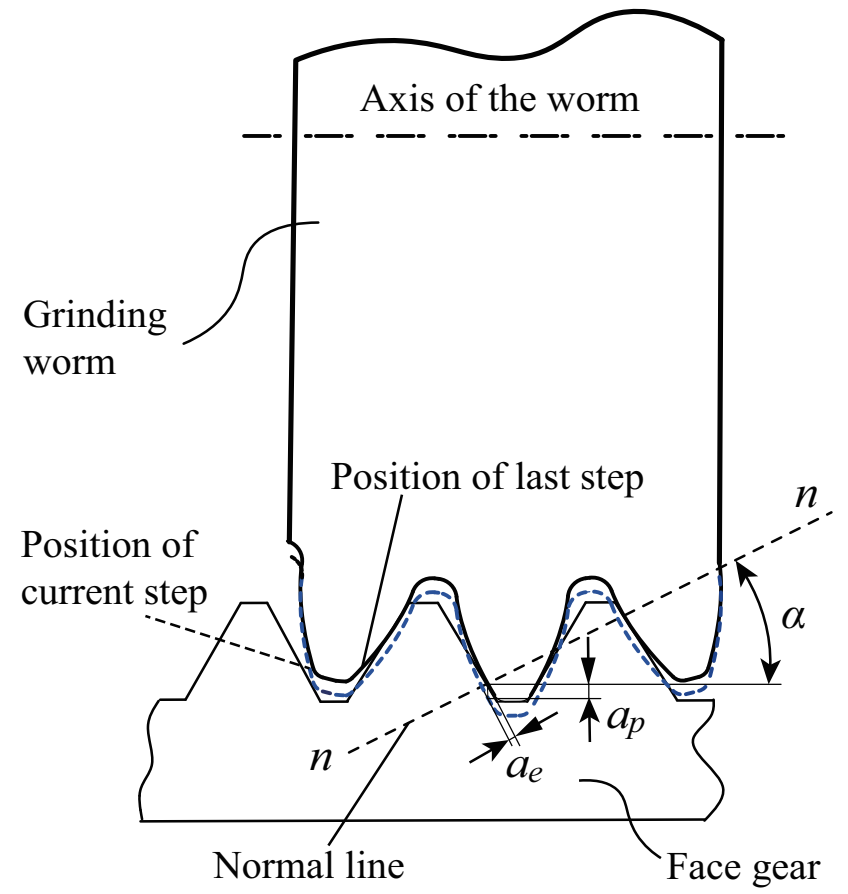

Figure 3: Schematic diagram of the grinding amounts in tooth depth direction and in normal direction.

\section{Mathematical model of grinding force and grinding heat of face gear}

\subsection{Mathematical model of grinding force of face gear and grinding worm wheel}

Based on the inclined surface grinding theory proposed by Guo [21], in different stages of tooth grinding, there are always deformation and friction between the abrasive particles and gear teeth, so the grinding force is mostly composed of the friction force and force resisting the deformation. The grinding force model of single abrasive particle can be written as:

$$
\left\{\begin{array}{l}
F_{g t}=F_{g t c}+F_{g t s} \\
F_{g n}=F_{g n c}+F_{g n s}
\end{array}\right.
$$

Where, $F_{g t}$ and $F_{g n}$ are the tangential grinding force and the normal grinding force of a single particle respectively; $F_{g t c}$ and $F_{g n c}$ are the tangential grinding force and the normal grinding force overcoming the deformation of metal materials; $F_{g t s}$ and $F_{g n s}$ are the tangential force and the normal grinding force generated by friction on the contact surface.

Figure 4 shows a schematic diagram of the deformation force of single abrasive particle. The shape of a single abrasive particle is approximately regarded as a cone with top half cone angle $\theta$. The grinding force $d F_{g c}$ within the range of angle $d \varphi$ is along the vertical direction of the cone surface, and it can be decomposed into the component force $d F_{g n c}$ along the normal direction of the tooth surface and the tangential component force $d F_{g t c}$.

The grinding force $d F_{g c}$ perpendicular to the conical surface of the abrasive particle can be expressed as:

$$
d F_{g c}=F_{p} d A
$$




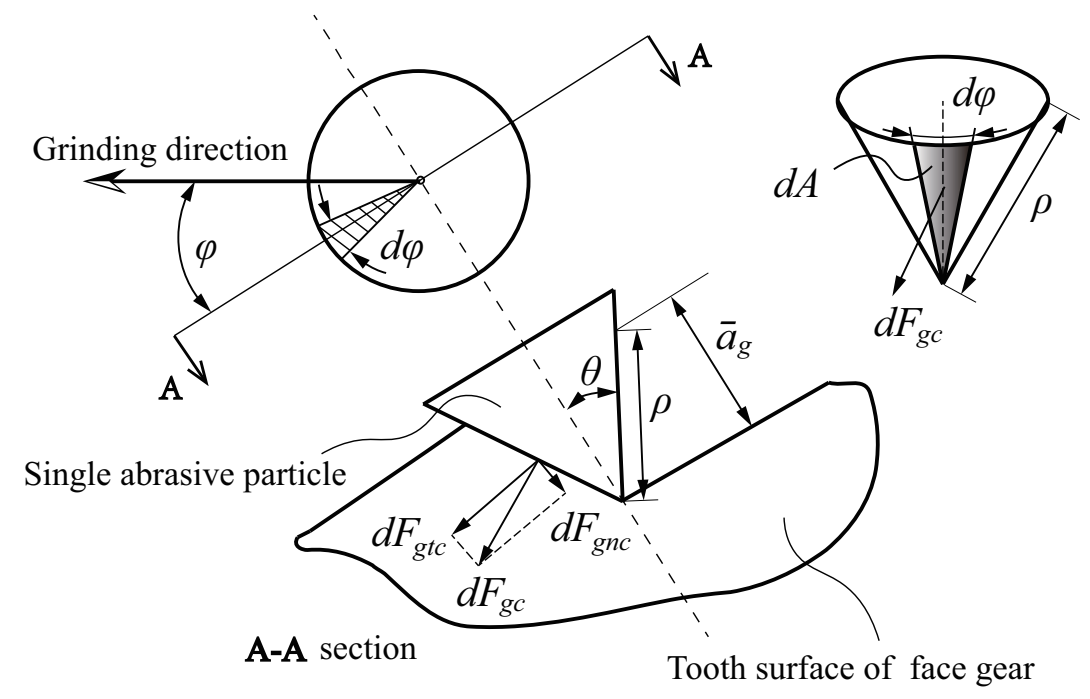

Figure 4: Schematic diagram of deformation force for a single-particle.

here, $F_{p}$ is the grinding force per unit grinding area; $d A$ is area of the fan-shaped conical surface of the abrasive particle within the range of angle $d \varphi$ (shaded area part in Figure 4); $\varphi$ is the angle between $d F_{g c}$ and the grinding direction; $\theta$ is half cone angle of a single abrasive particle.

The size of the fan-shaped contact area on the abrasive particle is:

$$
d A=\frac{1}{2} \rho^{2} \cdot \sin \theta d \varphi
$$

On the conical surface, the tangential grinding force $d F_{g t c}$ overcoming material deformation and the normal grinding force $d F_{g n c}$ overcoming material deformation of a single abrasive particle are expressed as:

$$
\left\{\begin{array}{l}
d F_{g t c}=d F_{g c} \cos \theta \cos \varphi \\
d F_{g n c}=d F_{g c} \sin \theta
\end{array}\right.
$$

By Integrating with Eq.(16) over the half conical surface of the abrasive particle, the tangential force and normal force of single particle for grinding deformation can be obtained as:

$$
\left\{\begin{array}{l}
F_{g t c}=\int d F_{g c} \cos \theta \cos \varphi=\int_{-\frac{\pi}{2}}^{\frac{\pi}{2}} \cos \varphi d \varphi \cdot\left[\frac{1}{2} \rho^{2} \sin \theta \cos \theta \cdot F_{p}\right]=F_{p} \bar{a}_{g}^{2} \tan \theta \\
F_{g n c}=\int d F_{g c} \sin \theta \cos \varphi=\int_{-\frac{\pi}{2}}^{\frac{\pi}{2}} \cos \varphi d \varphi \cdot\left[\frac{1}{2} \rho^{2} \sin ^{2} \theta \cdot F_{p}\right]=F_{p} \bar{a}_{g}^{2} \tan ^{2} \theta
\end{array}\right.
$$

here, $F_{p}$ is the grinding force per unit cutting area,

$$
F_{p}=\sigma_{0} \bar{A}_{g}^{-\varepsilon}
$$

where, $\sigma_{0}$ is the unit grinding force constant; $\bar{A}_{g}$ is average grinding layer area, and $\bar{A}_{g}=$ $\bar{a}_{g}^{2} \tan \theta ; \varepsilon$ is the correction coefficient, $\varepsilon \in(0.5,0.9)$.

For the conical abrasive particle model, there is friction in the area of the conical surface of the abrasive particle. The friction force of a single abrasive particle can be expressed as: 


$$
\left\{\begin{array}{l}
F_{g t s}=\mu \cdot H_{V} \cdot \bar{A}_{g} \\
F_{g n s}=H_{V} \cdot \bar{A}_{g}
\end{array}\right.
$$

where, $\mu$ is the friction coefficient, usually taken as $0.3 ; H_{V}$ is the Vickers hardness value of face gear material.

According to Eq.(17) and Eq.(19), the single abrasive particle grinding force can be obtained:

$$
\left\{\begin{array}{l}
F_{g t}=\sigma_{0} \bar{A}_{g}^{-\varepsilon} \cdot \bar{a}_{g}^{2} \cdot \tan \theta+\mu \cdot H_{V} \cdot \bar{A}_{g} \\
F_{g n}=\sigma_{0} \bar{A}_{g}^{-\varepsilon} \cdot \bar{a}_{g}^{2} \cdot \tan ^{2} \theta+H_{V} \cdot \bar{A}_{g}
\end{array}\right.
$$

Then the total tangential grinding force and normal grinding force in the contact ellipse area between the worm and the face gear are:

$$
\left\{\begin{array}{l}
F_{t}=S \cdot N_{d} \cdot F_{g t}=\frac{\pi a b}{4} \cdot N_{d} \cdot\left[\sigma_{0} \cdot\left(\frac{a_{p} \sin \alpha \cdot v_{w} \cdot \tan \theta}{2 N_{d} \cdot v_{s} \cdot a}\right)^{1-\varepsilon}+\mu \cdot H_{v} \cdot \bar{a}_{g}^{2} \tan \theta\right] \\
F_{n}=S \cdot N_{d} \cdot F_{g n}=\frac{\pi a b}{4} \cdot N_{d} \cdot\left[\sigma_{0} \cdot\left(\frac{a_{p} \sin \alpha \cdot v_{w} \cdot}{2 N_{d} \cdot v_{s} \cdot a}\right)^{1-\varepsilon} \cdot \tan ^{2-\varepsilon} \theta+H_{v} \cdot \bar{a}_{g}^{2} \tan \theta\right]
\end{array}\right.
$$

By combining equations (6), (8) and (21), the instantaneous grinding contact ellipse major axis length $a$, minor axis length $b$, tangential grinding force $F_{t}$ and normal grinding force $F_{n}$ can be solved.

\subsection{Thermal mathematical model for face gear grinding with grinding worm wheels}

Based on the Jaeger heat source theory[22], the heat source model in the grinding zone adopts a rectangular moving heat source. Assuming that the total heat flux density $Q_{t}$ is uniformly distributed in the grinding area during gear grinding, it can be calculated by the size of the instantaneous contact ellipse area and grinding power of the grinding wheel:

$$
Q_{t}=\frac{P_{m}}{S}=\frac{F_{t} \cdot v_{s}}{0.25 \pi \cdot b \cdot a}
$$

here, $P_{m}$ is the grinding power; $S$ is the area of the instantaneous contact ellipse; $v_{s}$ is the line speed of the grinding worm.

Because the grinding heat is transferred to the gear teeth, the grinding wheel, the wear debris and the coolant, the total heat flux density $Q_{t}$ can be considered to consist of four parts:

$$
Q_{t}=q_{w}+q_{s}+q_{c h}+q_{f}
$$

here, $q_{w}$ is the heat flux density adopted by the face gear teeth; $q_{s}$ is the heat flux density adopted by the grinding wheel; $q_{c h}$ is the heat flux density carried away by the grinding debris; $q_{f}$ is the heat flux density carried away by the coolant.

The heat flux density $q_{w}, q_{s}$ and $q_{f}$ can be expressed as the product of the thermal conduction or convection heat transfer coefficient and the maximum temperature $T_{\max }$ in the grinding zone. And, $q_{c h}$ can be expressed by the product of the thermal conductivity coefficient $h_{c h}$ and the melting 
point $T_{m p}$ of the material of the face gear. The total heat flux density in the grinding zone can be rewritten as:

$$
Q_{t}=h_{w} T_{\max }+h_{s} T_{\max }+\alpha_{f} T_{\max }+h_{c h} T_{m p}
$$

here, $h_{w}$ is the thermal conductivity coefficient of the heat entering the tooth surface; $h_{s}$ is the thermal conductivity coefficient of heat entering the grinding wheel; $\alpha_{f}$ is the convection heat transfer coefficient of the coolant; $h_{c h}$ is the thermal conductivity coefficient of the wear debris.

The thermal conductivity coefficient of the heat entering the tooth surface is:

$$
h_{w}=\frac{\left(k_{w} \rho_{w} c_{w}\right)^{0.5}}{C} \cdot \sqrt{\frac{v_{w}}{a}}
$$

here, $C$ can be taken as 1.0 for metallic materials; $\left(k_{w} \rho_{w} c_{w}\right)^{0.5}$ represents the thermodynamic parameter of workpiece material; $k_{w}, \rho_{w}$ and $c_{w}$ are the thermal conductivity, the material density and the specific heat capacity of the face gear material respectively.

Based on the analysis of the rectangular moving heat source model, the heat distribution ratio $R_{w}$ of the face gear can be obtained as:

$$
R_{w}=\frac{q_{w}}{q_{w}+q_{s}}=\frac{h_{w}}{h_{w}+h_{s}}
$$

According to Eq.(26), the thermal conductivity of the abrasive particles of the grinding wheel can be calculated by:

$$
h_{s}=\frac{h_{w}}{R_{w}}-h_{w}
$$

The convective heat transfer coefficient $\alpha_{f}$ in Eq.(24) of the coolant in the grinding area can be expressed as:

$$
\alpha_{f}=0.664 \rho_{f}^{0.5} \mu_{f}^{-0.16} \lambda_{f}^{0.67} c_{f}^{0.33} \cdot\left(\frac{v_{s}+v_{w}}{2 a}\right)^{0.5}
$$

where, $\rho_{f}$ is the density of the cooling liquid; $\mu_{f}$ is the dynamic viscosity coefficient of the cooling liquid; $c_{f}$ is the specific heat capacity of the cooling liquid; $\lambda_{f}$ is the thermal conductivity of the cooling liquid.

It is believed that the heat consumed by the wear debris can be calculated by the limit grinding energy[23]. The limit grinding energy is the energy required to melt the wear debris per unit weight, which can be expressed as:

$$
e_{c h}=\rho_{w} \cdot c_{w} \cdot T_{m p}
$$

The material removal rate of the face gear in unit time is equal to the product of $b, a_{e}$ and $v_{w}$. The heat consumed by the wear debris can be determined by the wear debris energy and the contact area:

$$
q_{c h}=e_{c h} \cdot \frac{b \cdot a_{e} \cdot v_{w}}{\frac{\pi}{4} \cdot a \cdot b}=\rho_{w} \cdot c_{w} \cdot T_{m p} \cdot \frac{4 a_{e} \cdot v_{w}}{\pi a}
$$

During wet grinding, the total heat flowing to the tooth surface and the coolant is expressed as:

$$
q_{w f}=q_{w}+q_{f}=\left(Q_{t}-q_{c h}\right) \cdot R_{w}
$$


The maximum temperature of the grinding zone under wet grinding condition is:

$$
T_{\max }=\frac{Q_{t}-q_{c h}}{h_{w}+h_{s}+\alpha_{f}}=\frac{Q_{t}-q_{c h}}{h_{w} / R_{w}+\alpha_{f}}
$$

\section{Finite element analysis of face gear grinding temperature field}

\subsection{Boundary conditions for the finite element model}

In order to simplify the finite element simulation process of grinding face gear with a worm wheel, some assumptions are made on the grinding conditions:

1) Assuming that the initial temperature of the face gear before grinding is equal to room temperature, which is $20^{\circ} \mathrm{C}$;

2) Assuming that the face gear material is isotropic and uniform, and the material parameters are independent of temperature except the thermodynamic parameters;

3) Assuming that the cooling of the coolant is uniform and effective during gear grinding;

Because all teeth of the face gear are ground by the same surface of the worm, they have good consistency. So, a FEM model only including five teeth is created for the transient temperature field of grinding the face gear. The set for boundary surface divisions are shown in Figure 5.

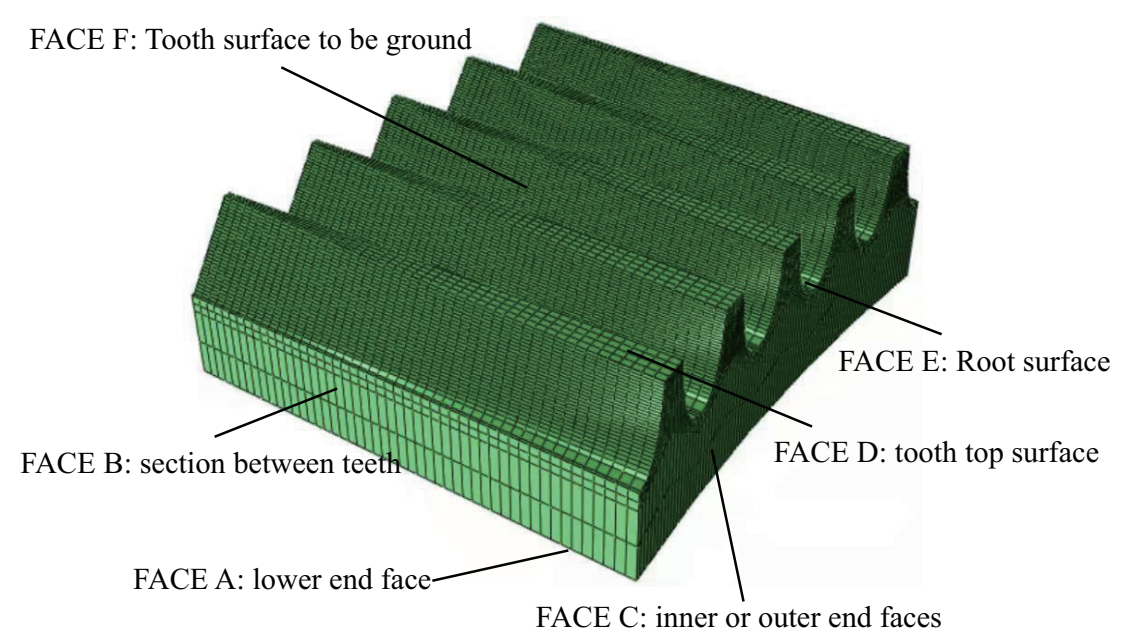

Figure 5: Boundary surfaces of the FEM model for the face gear.

\section{(1) FACE F}

When the grinding worm wheel is grinding the face gear, there is part of heat will flow into the tooth surface, $q_{w f}$ by Eq.(31) above. And there is also convective heat transfer between the face gear and the coolant, and the boundary conditions are:

$$
-\lambda\left(\frac{\partial T}{\partial \mathbf{n}}\right)=\alpha_{f}\left(T-T_{0}\right)-q_{w f}
$$

(2) FACE C, D and E 
FACE C, D and E represent the tooth top surface, tooth root surface and inner or outer end surfaces. Because these surfaces don't contact with the grinding worm, there is only convection heat transfer between the face gear and the air. The boundary conditions are:

$$
-\lambda\left(\frac{\partial T}{\partial \mathbf{n}}\right)=\alpha_{f}\left(T-T_{0}\right)
$$

(3) FACE A and B

The lower end face A and sections between teeth B are far away from the grinding surface, so there is almost no heat transfer on these surfaces, which can be ignored. FACE A and B can be considered as an adiabatic surface, and their boundary condition is:

$$
\frac{\partial T}{\partial \mathbf{n}}=0
$$

where, $T_{0}$ is the initial temperature value of the environment, taken as $20^{\circ} \mathrm{C} ; \mathrm{T}$ is the temperature value of the face gear body; $\lambda$ is the thermal conductivity of the face gear material; $\mathbf{n}$ is the normal direction vector of the heat exchange surface; $q$ is the heat flux density; $\alpha_{f}$ is the convective heat transfer coefficient.

The loading process of the transient temperature field for grinding face gear with a grinding worm wheel is shown in Figure 6. And the following steps are created in the FEM model.

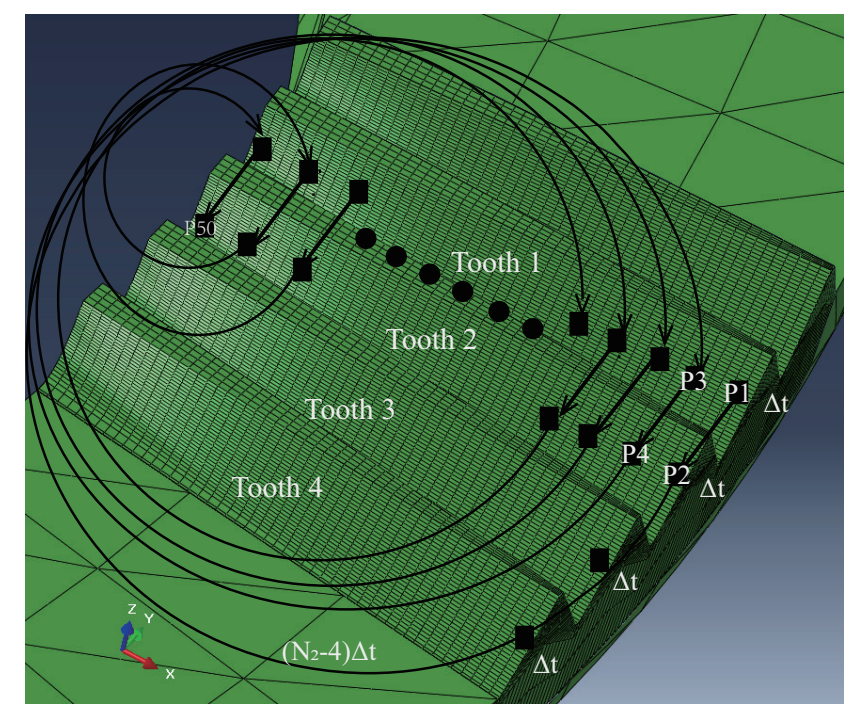

Figure 6: Schematic diagram of the heat load sequence for simulating grinding temperature field.

Step 1: For point P1 at the outer diameter of the tooth middle part of Tooth 1, solve the contact arc length $a$ and contact width $b$. The surface heat flux density $q_{w f}$ at this point is obtained according to Eq.(31). The loading time at this point is taken as one meshing period $\Delta t$ of the face gear:

$$
\Delta t=\frac{60}{v_{s}}
$$


Step 2: Delete the heat flow load applied to surface of Tooth 1 in Step 1. Take four points at the middle of the tooth of the outer diameter of Tooth 2 to Tooth 5 sequentially, apply the same surface heat flux density as same as Tooth 1 , and take the loading time as $\Delta t$.

Step 3: There is no heat flux input on the tooth surfaces for time of $\left(N_{2}-5\right) \times \Delta t$, which corresponds to time for the face gear to rotate an angle for $\left(N_{2}-5\right)$ teeth.

Step 4: Take a new point $\mathrm{P} 3$ on surface of Tooth 1, and the radial distance between point P3 and P1 is $\Delta r=v_{w} \cdot N_{2} \cdot \Delta t$, where $v_{w}$ is the feed speed of the grinding wheel along the tooth direction, and $N_{2}$ is the teeth number of the face gear. For point P3 on Tooth 1, recalculate $a, b$ and $q_{w f}$ etc. Apply the heat flux density load on point $\mathrm{P} 3$, and the time of duration for the load is $\Delta t$.

Repeat the above steps from Step 1 to Step 4 until the grinding wheel reach the inner diameter end of the face gear tooth, the grinding point will rotate around the axis of the face gear and move on the longitudinal direction of the tooth. Finally, the distribution of the grinding temperature field on the tooth surface of the face gear can be obtained.

\subsection{Simulation example of grinding temperature field}

The main parameters of the face gear selected in this paper and the mechanical and thermodynamic properties of its material (AISI9310 steel) are shown in Table 1. The grinding process parameters are shown in Table 2. The material of the grinding wheel is white corundum (IPA60G20VTX2), and its abrasive particle size is 80 .

Figure 7 shows temperature distribution for 3 different positions on the face gear tooth surface, which are located in inner radius, center and outer radius respectively. The maximum temperature values from the outer diameter to the inner diameter are 239 degrees, 275.9 degrees and 453.3 degrees respectively, so there is an upward trend from the outer diameter to the inner diameter.

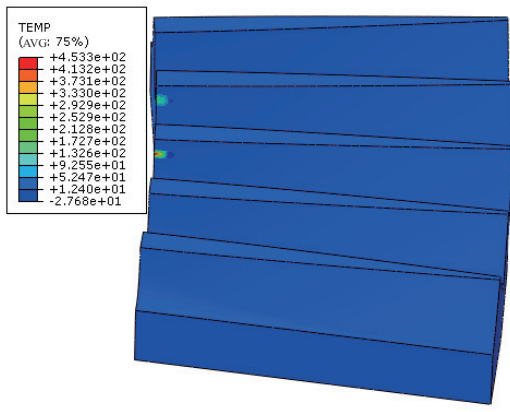

(a)

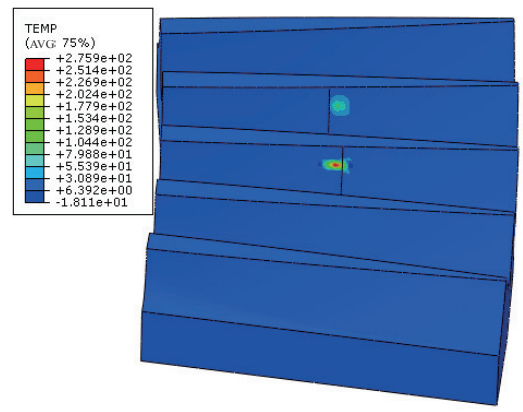

(b)

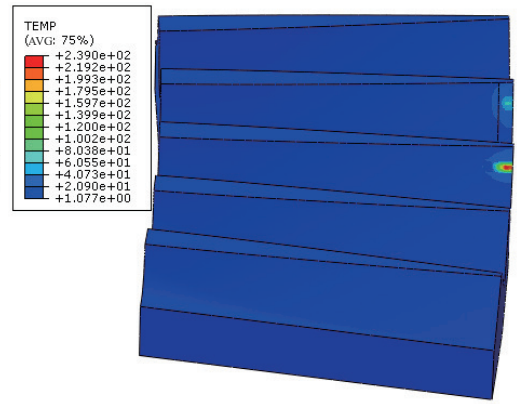

(c)

Figure 7: Grinding temperature distribution of tooth surface of face gear: (a) at the inner diameter of the middle of the tooth; (b) at the center of the tooth surface; (c) at the outer diameter of the middle of the tooth.

The theoretical calculation values of the maximum temperature of the grinding point in the middle of the tooth profile is obtained along tooth longitudinal direction by Eq.(32). Figure 8 shows the theoretical calculation values and the FEM simulation results. It can be seen from Figure 8 that the finite element simulation results are similar to the theoretical calculated values.

The influence of grinding process parameters (including single-step tooth depth feed $a_{p}$, rotating speed of the grinding wheel $v_{r}$, longitudinal feed speed of the grinding wheel $v_{w}$ ) on the 
Table 1: Parameters for face gear geometry, material properties and simulation applied.

\begin{tabular}{lcc}
\hline parameter name & value & unit \\
\hline normal modulus of gear, $m_{n}$ & 3.8 & $\mathrm{~mm}$ \\
number of face gear teeth, $N_{2}$ & 140 & - \\
angle of pressure, $\alpha$ & 25 & $\mathrm{deg}$ \\
crossed axis angle, $\gamma$ & 90 & $\mathrm{deg}$ \\
helical angle, $\beta$ & 0 & $\mathrm{deg}$ \\
addendum coefficient, $h_{a}^{*}$ & 1 & - \\
tip clearance coefficient, $c^{*}$ & 0.25 & - \\
external diameter, $D_{2}$ & 590 & $\mathrm{~mm}$ \\
width of tooth, $b_{w}$ & 50 & $\mathrm{~mm}$ \\
teeth number of shaper gear, $N_{s}$ & 22 & - \\
coefficient of expansion due to heat, $\alpha_{h}$ & $1.2 \mathrm{e}-5$ & $1 /{ }^{\circ} \mathrm{C}$ \\
modulus of elasticity, $E_{1}$ & $2.1 \mathrm{e} 11$ & $\mathrm{~Pa}$ \\
poisson ratio, $\mu_{1}$ & 0.277 & - \\
density, $\rho_{w}$ & 7810 & $\mathrm{~kg} / \mathrm{m}^{3}$ \\
thermal conductivity, $k_{w}$ & 45 & $\mathrm{~W} / \mathrm{m} \cdot{ }^{\circ} \mathrm{C}$ \\
material specific heat capacity, $c_{w}$ & 460 & $\mathrm{~J} / \mathrm{kg} \cdot{ }^{\circ} \mathrm{C}$ \\
percentage of effective abrasive particles, $f$ & 0.5 & - \\
abrasive particle volume fraction, $\nu$ & 0.25 & - \\
abrasive particle size, $M$ & 80 & - \\
friction coefficient between face gear surface and the abrasive particle, $\mu$ & 0.3 & - \\
initial temperature value of face gear and the environment, $T_{0}$ & 20 & ${ }^{\circ} \mathrm{C}$ \\
unit grinding force constant, $\sigma_{0}$ & 1080 & $\mathrm{MPa}$ \\
half cone angle of a single abrasive particle, $\theta$ & 45 & $\mathrm{deg}$ \\
correction coefficient of unit grinding force, $\varepsilon$ & 0.5 & - \\
Vickers hardness value of face gear material, $H_{V}$ & 269 & $\mathrm{~kg} / \mathrm{mm}^{2}$ \\
melting point of the material used for face gear, $T_{m p}$ & 1615 & ${ }^{\circ} \mathrm{C}$ \\
heat distribution ratio [24], $R_{w}$ & 0.65 & - \\
density of the cooling liquid, $\rho_{f}$ & 942 & $\mathrm{~kg} / \mathrm{m}^{3}$ \\
dynamic viscosity coefficient of the cooling liquid, $\mu_{f}$ & 5 & $\mathrm{~mm}{ }^{2} / \mathrm{s}$ \\
specific heat capacity of the cooling liquid, $c_{f}$ & 1009 & $\mathrm{~J} / \mathrm{kg} \cdot{ }^{\circ} \mathrm{C}$ \\
thermal conductivity of the cooling liquid, $\lambda_{f}$ & 0.13 & $\mathrm{~W} / \mathrm{m} \cdot{ }^{\circ} \mathrm{C}$ \\
\hline
\end{tabular}

Table 2: Gear grinding process parameters.

\begin{tabular}{lcc}
\hline parameter name & value & unit \\
\hline rotating speed of the grinding wheel, $v_{r}$ & 1600 & $\mathrm{r} / \mathrm{min}$ \\
feed speed along longitudinal direction of the grinding wheel, $v_{w}$ & 16 & $\mathrm{~mm} / \mathrm{min}$ \\
single-step feed amount along tooth depth, $a_{p}$ & 0.01 & $\mathrm{~mm}$ \\
diameter of the worm wheel, $D_{w}$ & 380 & $\mathrm{~mm}$ \\
\hline
\end{tabular}




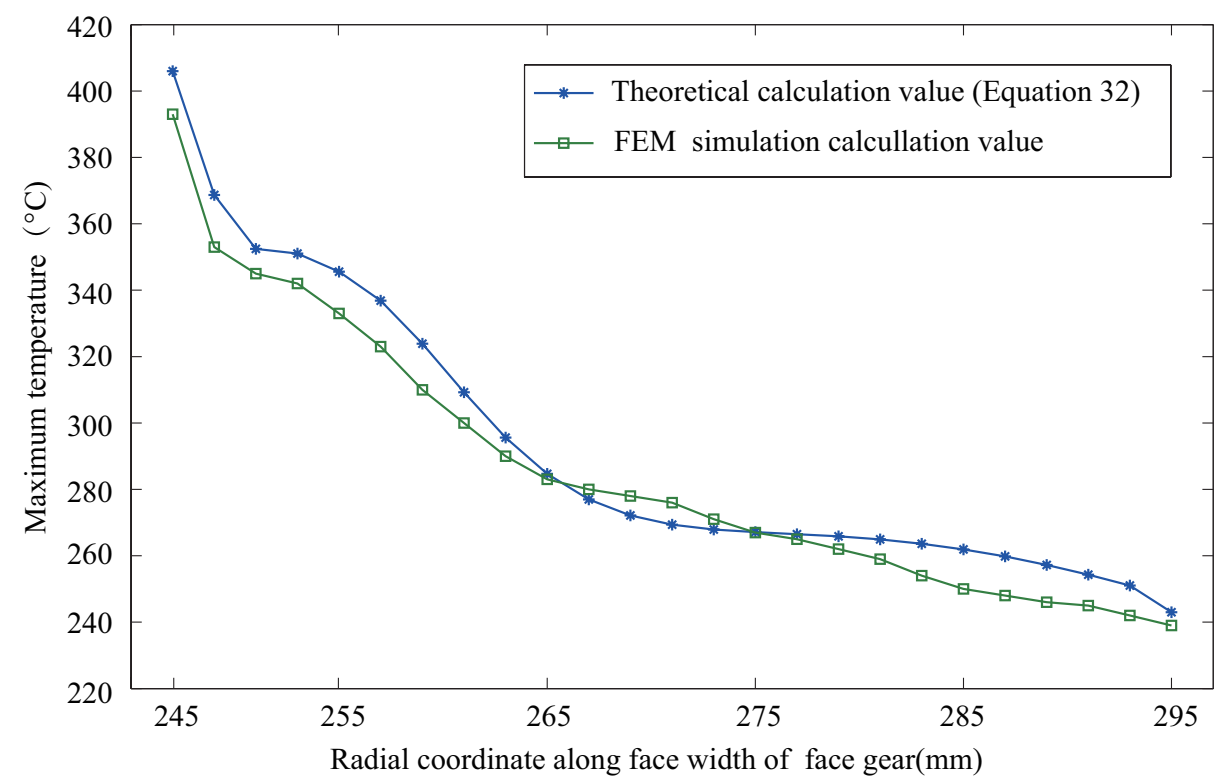

Figure 8: Comparison between theoretical calculation and simulation calculation results for maximum temperature along tooth longitudinal direction.

temperature of the center point of the face gear tooth surface is analyzed, as shown in Figure 9. The temperature of the grinding point increases with the increase of the single-step tooth depth feed $a_{p}$, because in the process of tooth grinding, the increase of the depth leads to the increase of the deformation force and friction force of the grinding chips, which results in the increase of the total heat flow in the grinding area. The temperature of the grinding point increases with the increase of the grinding wheel speed $v_{r}$, which is because the surface heat flux density of the grinding zone increases with the increase of the rotational speed of the grinding worm wheel during the grinding of the opposite gear. The temperature of the grinding point also increases with the increase of the grinding wheel feed rate $v_{w}$ along tooth longitudinal direction. This is because the increase of the longitudinal feed speed $v_{w}$ will increase the grinding tangential force between the grinding wheel and the face gear, so the heat flux density on the surface of the grinding zone increases, which results the maximum temperature of the grinding point. It should be noted that when parameters $a_{p}, v_{r}$ and $v_{w}$ are changing individually, the other two parameters are set as constant.

\section{Temperature test experiment of grinding face gear}

A grinding experiment of the face gear(listed in Tabel 1) and the temperature measurement of the tooth surface were carried out with the YK7363 gear grinding machine tool, as shown in Figure 10. A grinding worm wheel with IPA60-G20VTX2 type is used to grind the face gear, and the oil-based coolant is used for cooling the tooth surface. The infrared temperature measurement method is used to measure the temperature when the tooth surface of the face gear is being ground. The EasIR-4 infrared thermometer is choosen here, with temperature measurement range $-20^{\circ} \mathrm{C}$ to $500^{\circ} \mathrm{C}$, accuracy $\pm 2^{\circ} \mathrm{C}$, the emissivity 0.18 , and the ambient temperature is set to be $20^{\circ} \mathrm{C}$. In order to obtain more accurate results, the temperature values at the same position of multiple gear 


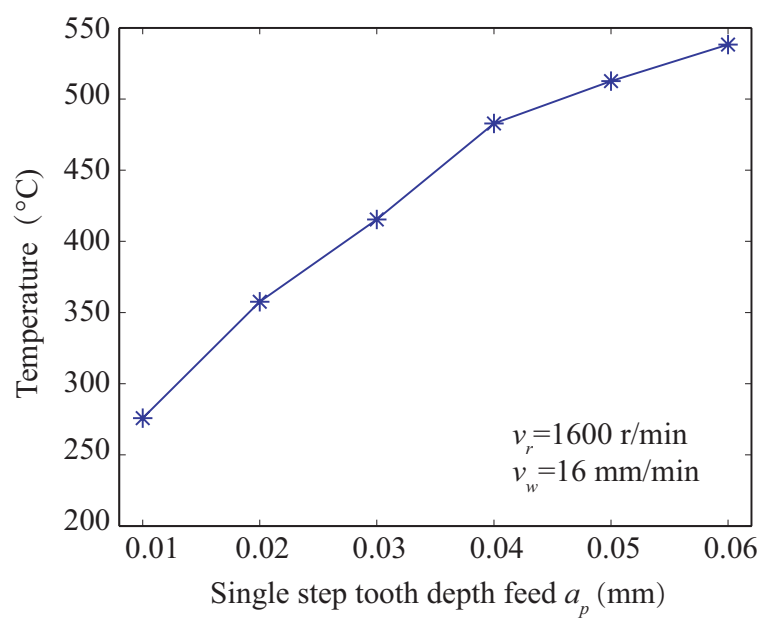

(a)

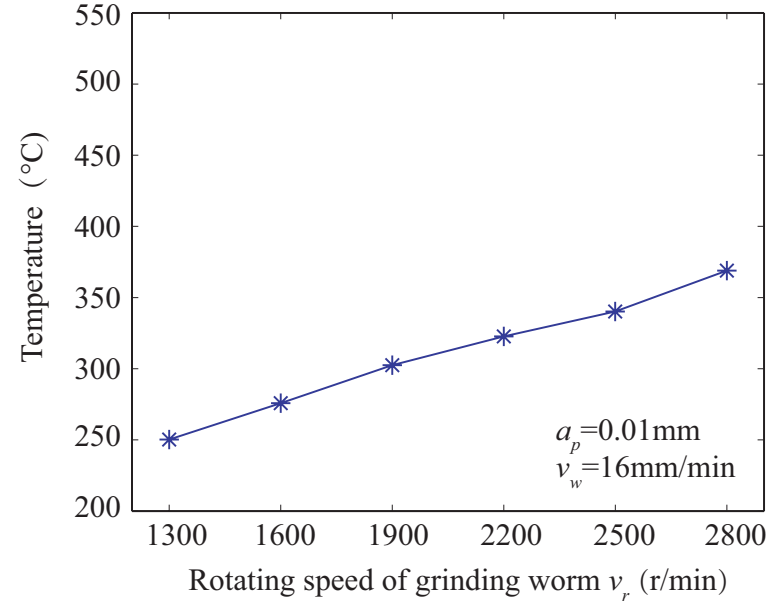

(b)

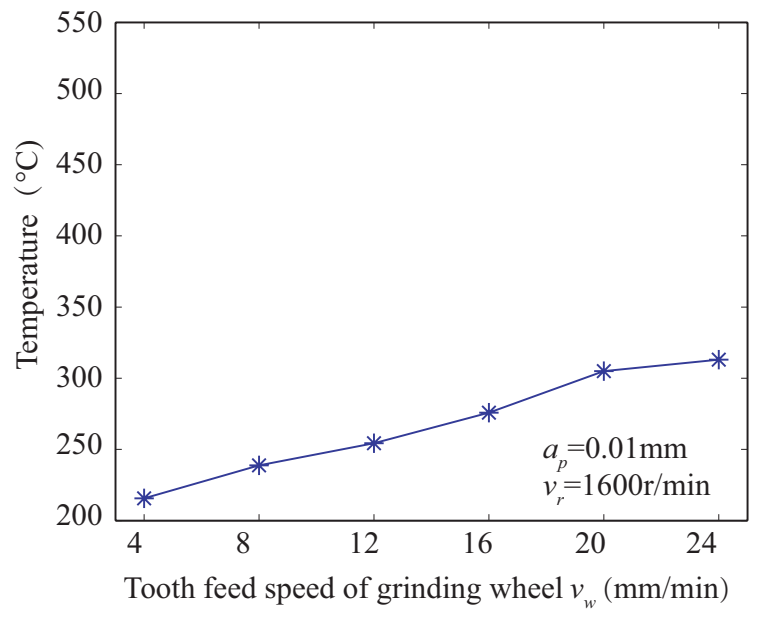

(c)

Figure 9: Influence of grinding process parameters on the maximum temperature of middle point on the tooth surface: (a) single-step tooth depth feed, $a_{p}$; (b) rotating speed of the grinding wheel, $v_{r}$; (c) feed speed of the grinding wheel along longitudinal direction, $v_{w}$. 
teeth are measured and then the average value is calculated as the final measurement temperature of the face gear.

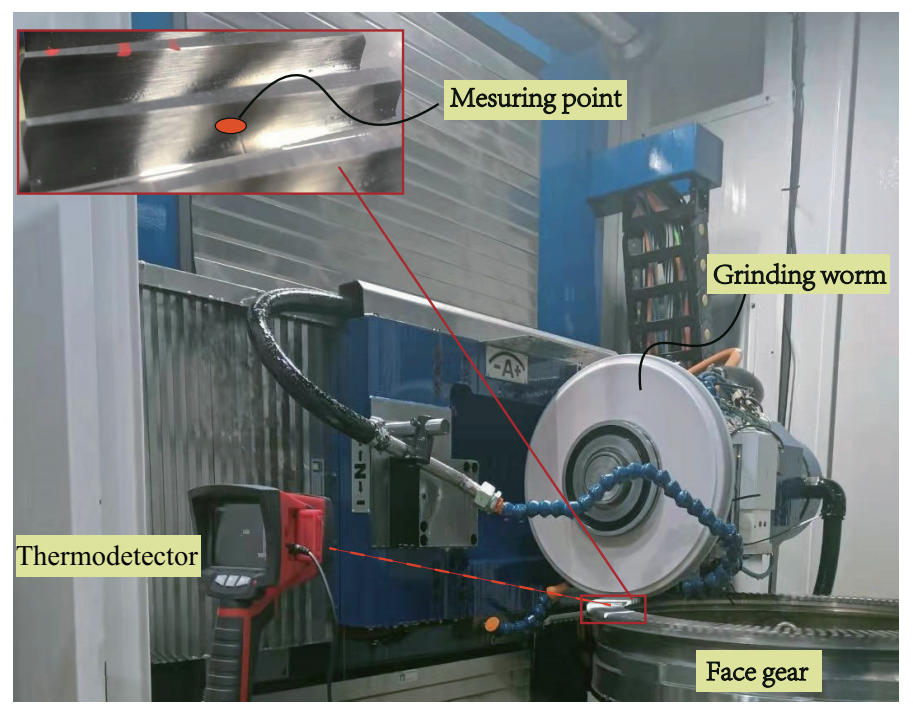

Figure 10: Temperature measurement for grinding face gear in YK7363 machine tool.

The center of the whole tooth surface of the face gear is selected as the measurement point for temperature measurement, as shown in Figure 7(b) and Figure 10. When a tooth surface is being ground by a worm wheel, it can't be measured by an infrared thermometer because the point is obscured by the worm. So, 0.1 second's delay is taken here for the gear teeth to rotate out of the grinding zone, that is about 4 teeth rotation time of the face gear. Therefore, in the finite element simulation results, the center temperature of the gear teeth after cooling for 0.1 second is also extracted here for comparison.

According to the orthogonal experimental method, nine groups of test parameter combination are designed for three grinding process parameters. Different combinations for the single-step tooth depth feed $a_{p}$, the grinding wheel rotating speed $v_{r}$ and the grinding wheel longitudinal feed speed $v_{w}$ are listed in Table 3. From the comparison data in Table 3, it can be seen that the finite element simulation calculation value of the grinding temperature at the tooth surface center point of each test scheme is similar to the measured value, and the maximum relative error is less than $20.3 \%$.

\section{Conclusions}

In this paper, a calculation model for determining tooth grinding temperature in the grinding face gear with a grinding worm wheel is proposed. The influence of the grinding process parameters on the grinding temperature field was studied, and the following conclusions were drawn.

(1) The equations for determining the contact arc length and width of the instantaneous grinding area of the face gear are deduced. The model for determining grinding force and grinding heat of face gear worm wheel is established, and the calculation formula of heat flux density and maximum temperature for grinding face gear tooth surface is obtained. 
Table 3: Simulation calculation and experiment results of gear grinding temperature for different grinding process parameters.

\begin{tabular}{ccccccc}
\hline $\begin{array}{c}\text { Test } \\
\text { number }\end{array}$ & $\begin{array}{c}\text { single step tooth } \\
\text { depth feed } \\
a_{p}(\mathrm{~mm})\end{array}$ & $\begin{array}{c}\text { grinding wheel } \\
\text { rotating speed } \\
v_{r}(r / \mathrm{min})\end{array}$ & $\begin{array}{c}\text { grinding wheel } \\
\text { longitudinal feed speed } \\
v_{w}(\mathrm{~mm} / \mathrm{min})\end{array}$ & $\begin{array}{c}\text { FEM } \\
\text { temperature } \\
/{ }^{\circ} \mathrm{C}\end{array}$ & $\begin{array}{c}\text { test } \\
\text { temperature } \\
/{ }^{\circ} \mathrm{C}\end{array}$ & $\begin{array}{c}\text { relative } \\
\text { error }\end{array}$ \\
\hline 1 & 0.01 & 1600 & 16 & 109.2 & 125 & $12.6 \%$ \\
2 & 0.01 & 1900 & 4 & 92.4 & 116 & $20.3 \%$ \\
3 & 0.01 & 2200 & 8 & 124.6 & 139 & $10.4 \%$ \\
4 & 0.02 & 1600 & 8 & 122.9 & 139 & $11.6 \%$ \\
5 & 0.02 & 1900 & 16 & 150 & 155 & $3.2 \%$ \\
6 & 0.02 & 2200 & 4 & 129.4 & 142 & $8.9 \%$ \\
7 & 0.04 & 1600 & 4 & 123.4 & 142 & $13.1 \%$ \\
8 & 0.04 & 1900 & 8 & 161.6 & 170 & $4.9 \%$ \\
9 & 0.04 & 2200 & 16 & 213.2 & 198 & $-7.7 \%$ \\
\hline
\end{tabular}

(2) A finite element model of the temperature field of grinding face gear is established. The influence of the grinding process parameters on the grinding temperature of the tooth surface is analyzed, and it is found that the grinding temperature will obviously increase with the increase of the single-step tooth depth feed, the grinding wheel rotating speed and the grinding wheel longitudinal feed speed.

(3) The measurement test of the grinding temperature of the face gear is finally carried out, and the maximum relative error between the experimental result and the simulation calculation result is less than $20.3 \%$, which shows the reliability of the simulation model.

\section{Funding}

This work was supported by the National Natural Science Foundation of China (51675424, 51075328),the Fundamental Research Funds for the Central Universities, the Natural Science Foundation of Shaanxi(2018JM5090), and the 111 Project (Grant no. B13044).

\section{Competing Interests}

The authors have no relevant financial or non-financial interests to disclose.

\section{Availability of data and material}

All data and parameters for the simulation model used in this paper have been provided.

\section{Code availability}

Not applicable. 


\section{Ethics approval}

Not applicable.

\section{Consent to participate}

All authors agree with the title, the content and author ranking of the paper..

\section{Consent for publication}

The work described in this paper is the result of an original research, it has not been published before, and it is not under consideration for publication elsewhere.

\section{Author Contributions}

All authors contributed to the study conception and design. Material preparation, data collection and analysis were performed by Hui Guo, Xuyang Wang and Ning Zhao. The first draft of the manuscript was written by Xuyang Wang and Hui Guo, and all authors commented on previous versions of the manuscript. All authors read and approved the final manuscript.

\section{References}

[1] Litvin F. L., Wang J. C., Bossler R. B., et al. Face-gear drives: Design, analysis, and testing for helicopter transmission applications. American Gear Manufacturers Association, Technical paper: 92-FTM2, 1992.

[2] Ming X., Zhao L., Wang W., et al. Finite Element Analysis of the Temperature Field of Face Gear Dish Wheel Grinding. Journal of Mechanical Transmission, 2015,39(06),58-61

[3] Outwater J. O., Shaw M. C. Surface Temperature in Grinding. Transaction of the ASME, 1952, 74: 73-78.

[4] Hahn R. S. On the nature of the grinding process. Proceedings of the 3rd International Machine Tool Design and Research Conference, 1962, (1): 129-154.

[5] Bei J.. Analysis and Research on Grinding Temperature. Journal of Shanghai Jiaotong University, 1964(3):57-73.

[6] Rowe W. B., Morgan M. N., Black S. C. E., et al. A Simplified Approach to Control of Thermal Damage in Grinding. CIRP Annals - Manufacturing Technology, 1996, 45(1):299302.

[7] Guo C., Wu Y., Vargheseb V., et al. Temperatures and Energy Partition for Grinding with Vitrified CBN Wheels. CIRP Annals - Manufacturing Technology, 1999, 48(1):247-250.

[8] Li J., Li J. C. M. Temperature distribution in workpiece during scratching and grinding. Materials Science \& Engineering A, 2005, 409(1/2):108-119. 
[9] Yan H., Ming X., Chen S., et al. Research and application analysis of grinding tooth temperature field of spiral bevel gear. Zhongguo Jixie Gongcheng/China Mechanical Engineering, 2007, 18(18): 2147-2152.

[10] Zhao Z., Qian N., Ding W., et al. Profile grinding of DZ125 nickel-based superalloy: Grinding heat, temperature field, and surface quality. Journal of Manufacturing Processes, 2020, $57: 10-22$.

[11] Yi J., Jin T., Zhou W., et al. Theoretical and experimental analysis of temperature distribution during full tooth groove form grinding. Journal of Manufacturing Processes, 2020, 58:101115 .

[12] Litvin F. L. , Hsiao C. L., Wang J. C., et al. Computerized Simulation of Generation of Internal Involute Gears and Their Assembly. Journal of Mechanical Design,1994, 116(3): 683-689.

[13] Litvin F. L., Gonzalez-Perez I., Fuentes A., et al. Design, generation and stress analysis of face-gear drive with helical pinion. Computer Methods in Applied Mechanics \& Engineering, 2005, 194(36/38):3870-3901.

[14] Li Z., Zhu R. Research on the base worm of the face gear hobbing tool. Mechanical Science and Technology, 2009, 28(1): 98-101.

[15] Guo H., Zhao N., Xiang Y., et al. Grinding method of face gear with six-axis CNC worm grinding machine. Chinese Journal of Mechanical Engineering, 2015, 51(011):186-194.

[16] Chu X., Wang Y., Du S., et al. An efficient generation grinding method for spur face gear along contact trace using disk CBN wheel. The International Journal of Advanced Manufacturing Technology, 2020, 110(5): 1179-1187.

[17] Litvin F. L., Fuentes A. Gear Geometry and Applied Theory. London:Cambridge University Press, 2004.

[18] Xu B. Elastoplastic mechanics and its application. Beijing:Machinery Industry Press, 1984.

[19] Karpakian S., Schmid S.R., Karpakian, etc. Manufacturing Engineering and TechnologyMachining. Beijing: Machinery Industry Press, 2004.

[20] Ren J., Hua D. Principles of Grinding. Xi' an:Northwestern Polytechnical University Press, 1988.

[21] Guo C., Campomanes M., Mcintosh D., et al. Optimation of continuous dress creep-feed form grinding process. CIRP Annals:manufacturing technology, 2003,52(1):259-262.

[22] Jaeger J. C. Moving Sources of Heat and the Temperature of Sliding Contacts. Proceedings of the royal society of New South Wales. 1942, 76: 203-224. 
[23] Malkin S. Grinding Technology: Theory and Applications of Machining with Abrasives. International Journal of Machine Tools and Manufacture, 1991, 31(3):435-436.

[24] Zhang Y. Metal Cutting Theory.Beijing: Aviation Industry Press, 1988.(in Chinese) 